\title{
GMP-Grade Manufacturing of T Cells Engineered to Express a Defined $\gamma \delta$ TCR
}

Trudy Straetemans ${ }^{1 \neq}$, Guido J. J. Kierkels ${ }^{1 \neq}$, Ruud Doorn', Koen Jansen', Sabine Heijhuurs ${ }^{1}$, Joao M. dos Santos ${ }^{1 \dagger}$, Anna D. D. van Muyden ${ }^{2}$, Henri Vie ${ }^{3,4}$, Béatrice Clemenceau ${ }^{3,4}$, Reinier Raymakers ${ }^{2}$, Moniek de Witte ${ }^{2}$, Zsolt Sebestyén ${ }^{1}$ and Jürgen Kuball ${ }^{1,2 *}$

OPEN ACCESS

Edited by:

Kenth Gustafsson,

University College London,

United Kingdom

Reviewed by:

John Anderson,

University College London,

United Kingdom

Daniel Olive,

Aix Marseille Université,

France

${ }^{*}$ Correspondence: Jürgen Kuball

j.h.e.kuball@umcutrecht.nl

tPresent address:

Joao M. dos Santos,

TILT Biotherapeutics Ltd,

Helsinki, Finland

*These authors have contributed equally to this work.

Specialty section:

This article was submitted to T Cell Biology,

a section of the journal

Frontiers in Immunology

Received: 07 February 2018

Accepted: 27 April 2018

Published: 30 May 2018

Citation:

Straetemans T, Kierkels GJJ,

Doorn R, Jansen K, Heijhuurs S, dos Santos JM, van Muyden ADD, Vie H, Clemenceau B, Raymakers $R$,

de Witte $M$, Sebestyén $Z$ and

Kuball J (2018) GMP-Grade

Manufacturing of

$T$ Cells Engineered to Express a Defined $\gamma \delta T C R$.

Front. Immunol. 9:1062. doi: $10.3389 /$ fimmu.2018.01062
${ }^{1}$ Laboratory of Translational Immunology, University Medical Center Utrecht, Utrecht University, Utrecht, Netherlands, ${ }^{2}$ Department of Hematology, University Medical Center Utrecht, Utrecht, Netherlands, ${ }^{3}$ CRCINA, INSERM 1232, CNRS, Université d'Angers, Université de Nantes, Nantes, France, ${ }^{4} \mathrm{CHU}$ de Nantes, Hôtel Dieu, UTCG, Nantes, France

$\gamma 9 \delta 2 T$ cells play a critical role in daily cancer immune surveillance by sensing cancermediated metabolic changes. However, a major limitation of the therapeutic application of $\gamma 9 \delta 2 T$ cells is their diversity and regulation through innate co-receptors. In order to overcome natural obstacles of $\gamma 9 \delta 2 T$ cells, we have developed the concept of $T$ cells engineered to express a defined $\gamma \delta T$ cell receptor (TEGs). This next generation of chimeric antigen receptor engineered $\mathrm{T}$ (CAR-T) cells not only allows for targeting of hematological but also of solid tumors and, therefore, overcomes major limitations of many CAR-T and $\gamma \delta \mathrm{T}$ cell strategies. Here, we report on the development of a robust manufacturing procedure of $\mathrm{T}$ cells engineered to express the high affinity $\mathrm{V} \gamma 9 \mathrm{~V} \delta 2 \mathrm{~T}$ cell receptor (TCR) clone 5 (TEG001). We determined the best concentration of anti-CD3/ CD28 activation and expansion beads, optimal virus titer, and cell density for retroviral transduction, and validated a Good Manufacturing Practice (GMP)-grade purification procedure by utilizing the CliniMACS system to deplete non- and poorly-engineered T cells. To the best of our knowledge, we have developed the very first GMP manufacturing procedure in which $\alpha \beta T C R$ depletion is used as a purification method, thereby delivering untouched clinical grade engineered immune cells. This enrichment method is applicable to any engineered $T$ cell product with a reduced expression of endogenous $\alpha \beta$ TCRs. We report on release criteria and the stability of TEG001 drug substance and TEG001 drug product. The GMP-grade production procedure is now approved by Dutch authorities and allows TEG001 to be generated in cell numbers sufficient to treat patients within the approved clinical trial NTR6541. NTR6541 will investigate the safety and tolerability of TEG001 in patients with relapsed/refractory acute myeloid leukemia, high-risk myelodysplastic syndrome, and relapsed/refractory multiple myeloma.

Keywords: $\gamma \delta \mathrm{TCR}$, cancer immunotherapy, GMP-manufacturing, $\mathrm{T}$ cell engineering, cancer, TEG

\section{INTRODUCTION}

Chimeric antigen receptor engineered T (CAR-T) cells are currently entering clinical practice with remarkable response rates resulting in multiple FDA approvals in 2017 (1). Major limitations of current clinical strategies are, however, that CAR-T cells rarely offer solutions to solid tumors. Another restriction of current CAR-T approaches is that target antigens are often present on healthy 
tissues. Therefore, we introduced the concept of metabolic cancer targeting through a defined high-affinity $\mathrm{V} \gamma 9 \mathrm{~V} \delta 2 \mathrm{~T}$ cell receptor (TCR) (2) and proposed to utilize T cells engineered to express a defined $\gamma \delta \mathrm{T}$ cell receptor (TEGs) as the next generation of CAR-T. V $\gamma 9$ V 22 TCRs sense spatial and conformational changes of butyrophilin 3A1 (CD277) and RhoB mediated by intracellular phosphoantigen accumulation (PAg). Transformed cells often have accumulated PAg due to a dysregulated mevalonate pathway, enabling $\gamma 9 \delta 2 \mathrm{~T}$ cells to recognize them $(3,4)$. The TEG concept allows for selecting the most potent V $\gamma 9$ V82TCR and targeting of liquid and solid tumors (5). TEGs also overcome the diversity of natural $\gamma 9 \delta 2 \mathrm{~T}$ cells (6) and avoid negative regulation of the V $\gamma 9 \mathrm{~V} \delta 2 \mathrm{TCR}$ through innate receptors of $\gamma 9 \delta 2 \mathrm{~T}$ cells (7). In addition, as V $\gamma 9 \mathrm{~V} 82 \mathrm{TCR}$ are introduced in both CD8 effector and CD4 helper cells, TEGs can deliver professional help through, e.g., maturing dendritic cells (5). For clinical testing of the TEG concept, we recently selected a highly tumor reactive Vy9V82TCR clone (clone 5) from the natural repertoire of a healthy individual (2). This particular Vy9V82TCR showed a strong reactivity toward a broad range of tumor cells within the TEG format, including primary leukemic blasts (8) as well as primary multiple myeloma cells (9). Due to the selection of a highaffinity V $\gamma 9 \mathrm{~V} \delta 2 \mathrm{TCR}$, TEGs also outperform natural $\gamma 9 \delta 2 \mathrm{~T}$ cells in terms of direct tumor recognition (2). For administration of TEGs in human, we recently proposed a purification step of TEGs by depletion of non- and poorly-engineered cells in order to further increase activity and definition of the product (8). However, a Good Manufacturing Practice (GMP)-grade procedure for a TEG drug product has not yet been defined. In this article, we describe the developmental process from a "research method" (8) to a manufacturing procedure that is fully compliant with GMP. Given that this process requires connecting two completely different worlds, a flexible research environment with a rigid GMP environment, the reported developmental process can be of high interest to researchers who aim at translating research findings to the clinic.

\section{MATERIALS AND METHODS}

\section{Production of Master Cell Bank (MCB) and Viral Vector Stock}

The retroviral vector supernatant was produced in 293Vec-RD114 cells, a 293SF-based packaging cell clone producing RD114 pseudotyped viral particles containing MP71:TCR $\gamma 5-T 2 A-T C R \delta 5$ transgene cassette, by BioNTech (Idar-Oberstein, Germany) $(10,11)$. To establish this packaging clone, first, a primary seed clone was established in a two-step transfection-transduction protocol. Candidate monoclonal cells were tested for the presence of the TCR transgene using qPCR. Transgene-positive clones were expanded to $14 \mathrm{~cm}$ Petri dishes in order to harvest supernatant. Primary seed clones were screened for virus titer production and the most productive cell clone (the producer cell line) was selected to grow a MCB. The MCB was released according to predefined criteria and stored in liquid nitrogen. Sequence integrity of the transgene was confirmed by sequence analysis of the MCB and TEG001 drug product samples.

\section{Preparation of Leukapheresis Material}

Patient-derived mononuclear cells obtained by leukapheresis were cryopreserved in freezing medium [sodium chloride $(\mathrm{NaCl})$ $0.9 \%$ with $10 \%$ dimethylsulfoxide and $5 \%$ human albumin (HA)]. The material was thawed at $37^{\circ} \mathrm{C}$ and mixed with five volumes of leukapheresis thaw medium [X-VIVO 15 chemically defined medium without gentamicin and phenol red (Lonza, Breda, The Netherlands), hereafter, called X-VIVO 15, supplemented with $10 \% \mathrm{HA}$. After washing, cells were resuspended in culture medium with cytokines (X-VIVO 15 medium with 5\% human serum), $1.7 \times 10^{3} \mathrm{IU} / \mathrm{ml}$ of MACS GMP Recombinant Human interleukin (IL)-7 (Miltenyi Biotec, Bergisch Gladbach, Germany), and $1.5 \times 10^{2} \mathrm{IU} / \mathrm{ml}$ MACS GMP Recombinant Human IL-15 (Miltenyi Biotec).

\section{Activation of T Cells}

The cell suspension was diluted to a concentration of $1 \times 10^{6}$ $\mathrm{T}$ cells/ml with culture medium containing cytokines. T cells were activated by adding anti-CD3/CD28 Dynabeads (Thermo Fisher Scientific, Etten-Leur, the Netherlands) to the cell suspension at a bead to cell ratio of 1:5 or otherwise indicated, homogenizing for $30 \mathrm{~min}$ at room temperature (RT) under rocking conditions, and subsequently incubating for $40-50 \mathrm{~h}$ at $37^{\circ} \mathrm{C} / 5 \% \mathrm{CO}_{2}$.

At Day 2, activated T cells were harvested by centrifugation and subsequently resuspended in culture medium containing cytokines. Manual cell count using trypan blue exclusion was performed and the cell suspension was further diluted with culture medium containing cytokines to a target concentration of $0.5 \times 10^{6}$ viable cells $/ \mathrm{ml}$.

\section{Transduction}

Non-tissue culture treated 24-well plates (Thermo Fisher Scientific) were coated with Retronectin (Takara Bio, SaintGermain-en-Laye, France) at saturating conditions and incubated for $40-50 \mathrm{~h}$ at $2-8^{\circ} \mathrm{C}$. At the day of transduction, the coated plates were incubated for $30 \mathrm{~min}$ at $37^{\circ} \mathrm{C}$ with $0.4 \% \mathrm{HA}$ in $\mathrm{NaCl}, 0.9 \%$ to block unspecific binding. Next, viral supernatant was thawed at RT and diluted 1:1 with X-VIVO 15 medium, or as described in the relevant figure. RetroNectin-coated plates were coated with $2.0 \mathrm{ml} /$ well diluted viral supernatant by spinning for $90 \mathrm{~min}$ at $500 \times g$ at RT (one-spin hit transduction). The remaining supernatant was aspirated and discarded. Subsequently, $1 \times 10^{6}$ activated cells were added per well of the viral-supernatant-coated plates $\left(2.0 \mathrm{ml}\right.$ cell suspension of $0.5 \times 10^{6}$ cells $\left./ \mathrm{ml}\right)$ and incubated for $16-24 \mathrm{~h}$ at $37^{\circ} \mathrm{C} / 5 \% \mathrm{CO}_{2}$.

At Day 3, transduced cells were harvested from the 24-well plate, centrifuged, and subsequently resuspended in culture medium with cytokines. Manual cell count was performed and the cell suspension was further diluted with culture medium with cytokines to a final target concentration of $0.25 \times 10^{6}$ viable cells $/ \mathrm{ml}$. The cell suspension was transferred to MACS GMP Cell Differentiation Bag(s) (Miltenyi Biotec) and incubated for $60-80 \mathrm{~h}$ at $37^{\circ} \mathrm{C} / 5 \% \mathrm{CO}_{2}$.

\section{Expansion of Transduced Cells}

Transduced cells were cultured from Day 3 to Day 13. At Day 6, samples from cell suspension were taken to determine the 
concentration of viable cells by trypan blue exclusion. Transduction efficiency was determined by flow cytometry $\% \gamma \delta \mathrm{TCR}$ positive T cells). The cell suspension was centrifuged and cultured in fresh culture medium supplemented with cytokines to a target concentration of $0.25 \times 10^{6}$ viable cells $/ \mathrm{ml}$ and incubated for $36-48 \mathrm{~h}$ at $37^{\circ} \mathrm{C} / 5 \% \mathrm{CO}_{2}$.

At Day 8, manual cell count was performed to determine the concentration of viable cells by trypan blue exclusion. The cell suspension, if applicable, was diluted to a target viable cell concentration of $1 \times 10^{6}$ cells $/ \mathrm{ml}$ with fresh culture medium without cytokines. The total volume of cell suspension was then supplemented with half the cytokine concentration. The cell suspension was incubated for $36-48 \mathrm{~h}$ at $37^{\circ} \mathrm{C} / 5 \% \mathrm{CO}_{2}$.

At Day 10, manual cell count was performed to determine the concentration of viable cells by trypan blue exclusion. The cell suspension was centrifuged and further diluted with fresh culture medium supplemented with cytokines to a target viable cell concentration of about $1 \times 10^{6}$ cells $/ \mathrm{ml}$. The cell suspension was incubated for $60-80 \mathrm{~h}$ at $37^{\circ} \mathrm{C} / 5 \% \mathrm{CO}_{2}$.

\section{Purification of TEG001 by Research MACS Depletion of Non- and Poorly-Engineered Immune Cells}

pMP71: $\gamma$ TCR-T2A- $\delta$ TCR-transduced T cells were incubated with biotin-labeled anti- $\alpha \beta$ TCR antibody (clone BW242/412; Miltenyi Biotec), followed by incubation with an anti-biotin antibody coupled to magnetic beads (anti-biotin MicroBeads; Miltenyi Biotec). Next, the cell suspension was applied to an LD column in a QuadroMACSTM Separator. $\alpha \beta$ TCR-positive T cells were depleted by MACS cell separation according to the manufacturer's protocol (Miltenyi Biotec).

\section{Purification of TEG001 by CliniMACS Depletion of Non- and Poorly-Engineered Immune Cells}

At Day 13, the cell suspension volume was reduced, when necessary, to $150-200 \mathrm{ml}$ by removing supernatant after centrifugation. Anti-CD3/CD28 beads were removed from the cell suspension of transduced $\mathrm{T}$ cells using a magnet (Dynamag Cell Therapy Systems magnet).

The cell suspension was processed as follows:

a) Washed with phosphate buffered saline/ethylenediaminetetracetic Acid/HA buffer (PBS/EDTA buffer with $0.5 \% \mathrm{HA}$ ) and adjusted to a volume of $95 \mathrm{ml}$ with PBS/EDTA/HA buffer.

b) Incubated with $7.5 \mathrm{ml}$ of TCR $\alpha \beta$-Biotin reagent (biotinlabeled anti $\alpha \beta$ TCR antibody (clone BW242/412; Miltenyi Biotec)) for $30 \mathrm{~min}$ on a swivel plate.

c) Washed with $600 \mathrm{ml}$ PBS/EDTA/HA buffer and after centrifugation, the volume was adjusted to $190 \mathrm{ml}$ with PBS/EDTA/ HA buffer.

d) Incubated with $15 \mathrm{ml}$ of anti-Biotin reagent (anti biotin antibody coupled to magnetic beads) for $30 \mathrm{~min}$ on a swivel plate.

e) Washed by adding PBS/EDTA/HA buffer to a volume of about $600 \mathrm{ml}$ and removing supernatant after centrifugation.
Subsequently, PBS/EDTA/HA buffer was added to a volume of about $200 \mathrm{ml}$ and the $\alpha \beta$ TCR-expressing T cells (non- and poorly-engineered cells) were depleted using a CliniMACS Plus instrument (Magnetic Activated Cell Sorting) cell separation, program "depletion 3.1."

f) Washed twice with infusion medium $(\mathrm{NaCl} 0.9 \%$ for infusion with $4 \% \mathrm{HA}$ ) and resuspended in infusion medium to obtain $25 \mathrm{ml}$ TEG001 drug substance.

\section{Cells and Cell Lines}

Daudi (CCL-213) was obtained from the American Type Culture Collection and ML-1 was obtained from Sigma-Aldrich (Zwijndrecht, the Netherlands). Cell lines were authenticated by short tandem repeat profiling/karyotyping/isoenzyme analysis. All cells were passaged for a maximum of 2 months, after which new seed stocks were thawed for experimental use. In addition, all cell lines were routinely verified by growth rate, morphology, and/or flow cytometry and tested negative for mycoplasma using MycoAlert Mycoplasma Kit. Daudi and ML-1 were cultured in RPMI $+1 \%$ Pen/Strep $+10 \%$ FCS (Bodinco, Alkmaar, the Netherlands). Peripheral blood mononuclear cells (PBMCs) were isolated from buffy coats or apheresis material obtained from the Sanquin Blood Bank (Amsterdam, the Netherlands).

\section{Flow Cytometry}

Antibodies used for flow cytometry include: pan- $\gamma \delta T C R-P E$ (clone IMMU510; Beckman Coulter, Woerden, the Netherlands), pan- $\alpha \beta$ TCR-APC (clone IP26; eBioscience, Thermo Fisher Scientific), CD4-V450 (clone RPA-T4; BD Biosciences), CD8 $\alpha$ PerCP-Cy5.5 (RPA-T8; Biolegend), CD3-eFluor 450 (OKT-3; eBioscience), CD45-FITC (2D1; BD Biosciences), CD16-FITC (3G8; BD Biosciences), CD56-FITC (MY31; BD Biosciences), CD27-APC-eFluor780 (O323; eBioscience), CD45RO-PE-Cy7 (UCHL-1; BD Biosciences). All samples were analyzed on a BD LSRFortessa using FACSdiva software (BD Biosciences).

\section{ELISPOT and ELISA Assays}

IFN $\gamma$ ELISPOT was performed as previously described $(5,6)$. Briefly, 15,000 TCR-transduced or mock-transduced (TEG-LM1) $\mathrm{T}$ cells and 50,000 target cells (ratio 0.3:1) were cocultured for $24 \mathrm{~h}$ in nitrocellulose-bottomed 96-well plates (Merck, SchipholRijk, the Netherlands), pre-coated with anti-IFN $\gamma$ antibody (clone 1-D1K) (Mabtech, Nacka Strand, Sweden). Plates were washed and incubated with a second biotinylated anti-IFN $\gamma$ antibody (clone 7-B6-1) (Mabtech) followed by streptavidin-HRP (Mabtech). IFN $\gamma$ spots were visualized with tetramethylbenzidine substrate (Sanquin) and the number of spots was quantified using ELISPOT Analysis Software (Aelvis, Hannover, Germany). IFNy ELISA was performed using ELISA-ready-go! Kit (eBioscience) following manufacturer's instructions. Effector and target cells (E:T 15,000:15,000) were incubated for $24 \mathrm{~h}$ in the presence of pamidronate when indicated.

\section{Statistical Analyses}

Differences were analyzed using indicated statistical tests in GraphPad Prism 7 for Windows (GraphPad Software Inc., La Jolla, CA, USA). 


\section{RESULTS}

\section{Defining Optimal Activation of Primary T Cells With Anti-CD3/CD28 Coated Beads}

Stimulation of T cells with immobilized anti-CD3 and anti-CD28 antibodies provides both an antigen stimulus and co-stimulation for optimal $\mathrm{T}$ cell activation and expansion (12). Consequently, anti-CD3/CD28-coated beads are widely applied to engineer cellular products for different types of adoptive $\alpha \beta \mathrm{T}$ cell therapies (13-16). The optimal anti-CD3/28 bead to CD3+ T cell ratio for activation, transduction with viral supernatant, and expansion of engineered immune cells is, however, frequently dependent on the specific transgene and production process. In order to define the best anti-CD3/28 bead to CD3+ $\mathrm{T}$ cell number for engineering TEGs, PBMCs were first analyzed for CD3+ $\mathrm{T}$ cell content by flow cytometry, and then incubated with various ratios of anti-CD3/CD28 beads in the presence of the cytokines interleukin (IL)-7 and IL-15. As a control stimulus, soluble OKT-3 and IL-2 was used. Next, T cells were transduced with non-GMP grade retroviral supernatant and expanded as described in the Section "Materials and Methods." After 10 days, the total number of TEGs, defined as double positive TEGs when expressing $\gamma \delta$ TCRs and $\alpha \beta T C R s$ or single positive TEGs when expressing $\gamma \delta$ TCRs only, were assessed by flow cytometry. The mean total cell number of single and double positive TEGs ranged from 2 to $6 \times 10^{6}$ cells when stimulated with anti-CD3/28 beads, and peaked at an anti-CD3/28 bead to T cell ratio of 1:5, while our standard OKT3 research protocol delivered $3 \times 10^{6}$ cells (Figure 1). Due to the limited number of replicates, when performing a Mann-Whitney $U$-test, the difference between none of the conditions was significant $(p>0.05)$. A 1:5 bead to $\mathrm{T}$ cell ratio was chosen for the activation of T cells in all following TEG manufacturing procedures. This ratio is sufficient to activate $\mathrm{T}$ cells and is substantially lower in numbers than advised by the manufacturer and, therefore, saves costs during the future production procedures.

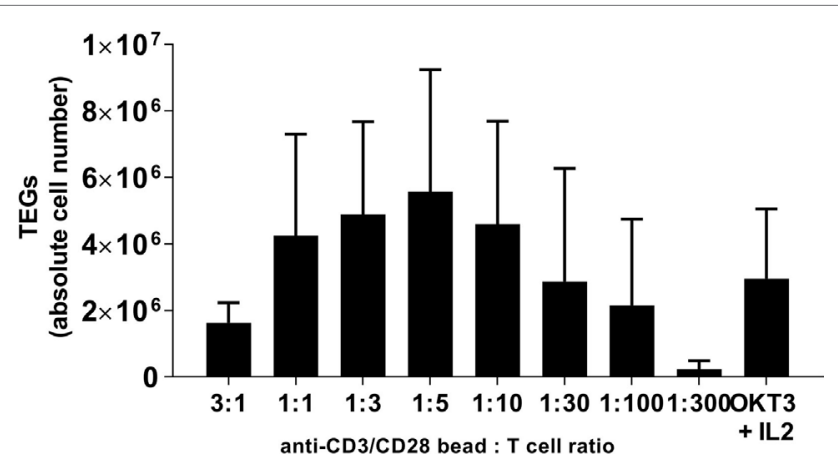

FIGURE 1 | TEG yield depends on the optimal anti-CD3/CD28 bead to T cell ratio at the day of $T$ cell activation. Multiple anti-CD3/CD28 bead to $T$ cell ratios were tested and compared with respect to total TEG yield at day 10 . After activation, transduction and expansion TEG numbers were defined by combining viable cell count with flow cytometry for $\gamma \delta \mathrm{TCR}+\mathrm{T}$ cell percentage. OKT3 + IL2 served as a control activation and expansion stimulus. Mean absolute cell number $+\mathrm{SD}$ is shown, $n=2-3$. The differences according to Mann-Whitney $U$ tests are not significant $(p>0.05)$.

\section{Selection of a GMP-Grade Retroviral Producer Cell Clone}

One of the most critical raw materials of the TEG manufacturing process is the viral vector supernatant used to transduce the $\mathrm{T}$ cells. Selection of a potent GMP-grade cell clone that produces the retroviral vector encoding the $\gamma \delta \mathrm{TCR}$ is, therefore, critical for the success of the GMP-grade transduction process. The retroviral vector supernatant was produced using 293SF-based packaging cells, 293Vec-RD114, by BioNTech (10,11). A large number of engineered producer cell clones were generated and the virus titer in the supernatant was assessed by titration experiments on Jurkat cells and analysis of $\gamma \delta$ TCR positive cells by flow cytometry (Figure 2A). The 8 best clones were selected for the second round of testing. Two additional clones from the upper midfield $(\# 8$, \#62) were added to confirm the ranking (Figure 2B). Clone \#73 was selected as the best GMP-grade retroviral producer cell line and was, therefore, further expanded and the titer was assessed before and after $0.45 \mu \mathrm{m}$ filtration of the supernatant from different harvesting runs (Figure 2C). Filtration was performed in order to eliminate cell debris, a key step for generating GMP grade viral supernatant. This associated, however, with an up to sixfold reduction in viral particles in different harvesting runs (Figure 2C).

\section{Virus Titer Impacts Transduction Efficiency of Primary T Cells}

In the manufacturing of genetically modified cellular medicines, there is a strong relationship between transduction efficiency and the ability to produce sufficient cell numbers that meet predefined quality criteria (17). To optimize the production process we, therefore, assessed the amount of virus needed for optimal efficiency in a one-hit transduction. Viral supernatant generated in different pre-GMP proof runs from producer cell line clone $\# 73$ was used with virus titers ranging from $8.7 \times 10^{3}$ to $2.7 \times 10^{6}$ infectious particles (ip) per milliliters. Transduction efficiency was evaluated after 7 and 10 days of expansion with the optimized 1:5 anti-CD3/28 bead to $\mathrm{T}$ cell ratio. The percentage of TEGs was determined by flow cytometry using a pan- $\gamma \delta$ TCR antibody. The total number of both single and double positive TEGs was determined. Viral supernatant containing $1 \times 10^{6} \mathrm{ip} / \mathrm{ml}$ provided transduction efficiencies of $60-70 \%$ TEGs (Figure 3A). The majority of TEGs showed high expression levels of $\gamma \delta \mathrm{TCR}$ while being negative for $\alpha \beta T C R$ due to the successful competition of the introduced $\gamma \delta$ TCR chains against endogenous $\alpha \beta$ TCRs for components of the $\mathrm{CD} 3$ complex as reported (8). Thus, virus titers around $1 \times 10^{6} \mathrm{ip} / \mathrm{ml}$ are sufficient for the generation of TEGs.

\section{Impact of T Cell Density on Transduction and Expansion Efficiency}

It has been suggested that the density of activated $\mathrm{T}$ cells during the transduction procedure influences the transduction efficiency (18). Therefore, the optimal cell concentration during transduction was investigated within the context of four different virus titers (range $0.03-1.5 \times 10^{6} \mathrm{ip} / \mathrm{ml}$ ), and five different $\mathrm{T}$ cell densities (range $0.1-2.0 \times 10^{6} / \mathrm{ml}$ ). During the expansion phase, $\mathrm{T}$ cell densities were adjusted to defined concentrations at day 3 


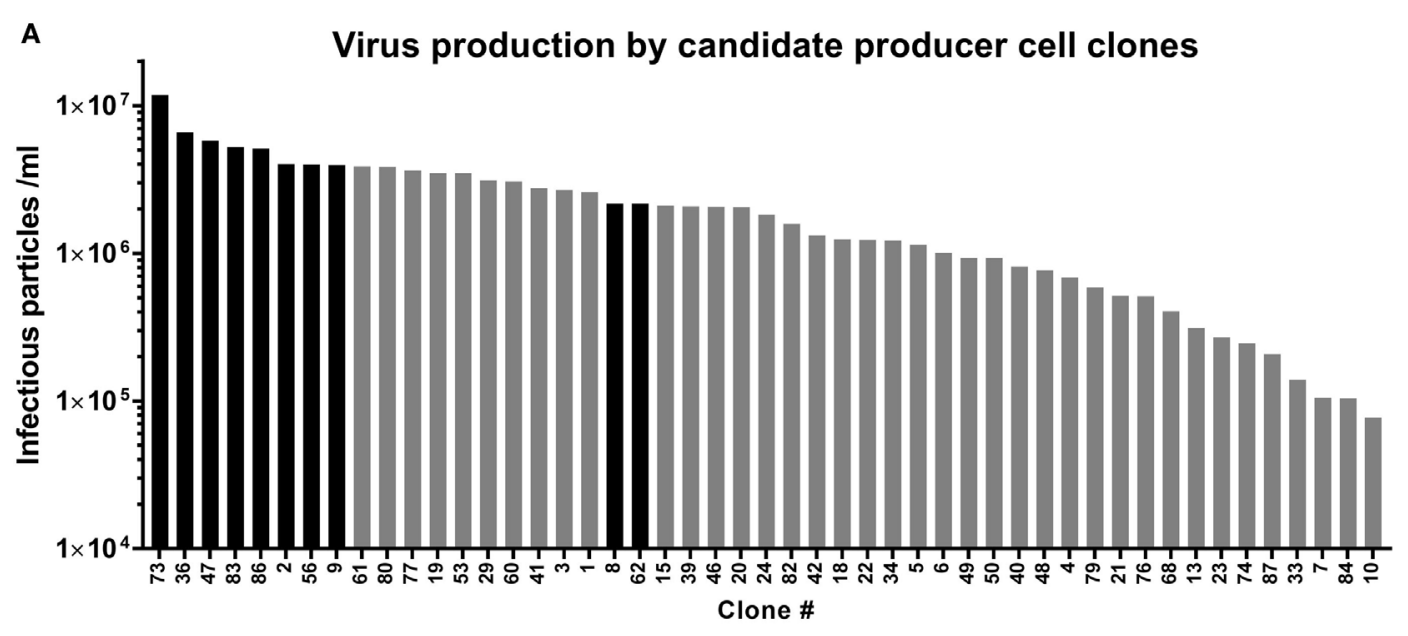

B Titer of 10 selected clones

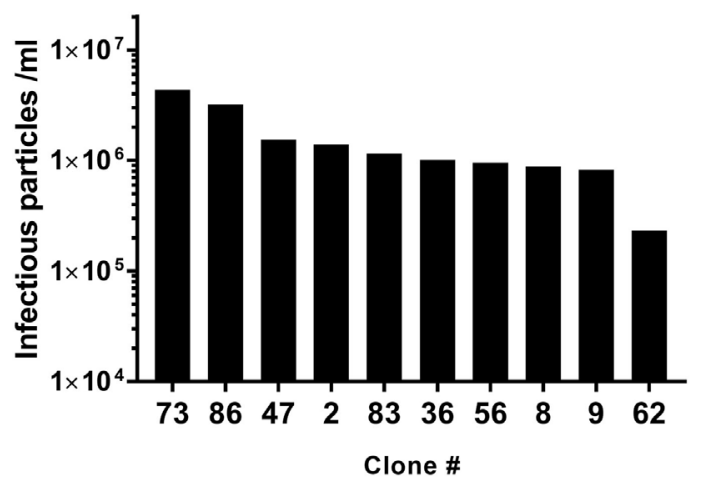

C

Titer of clone \#73

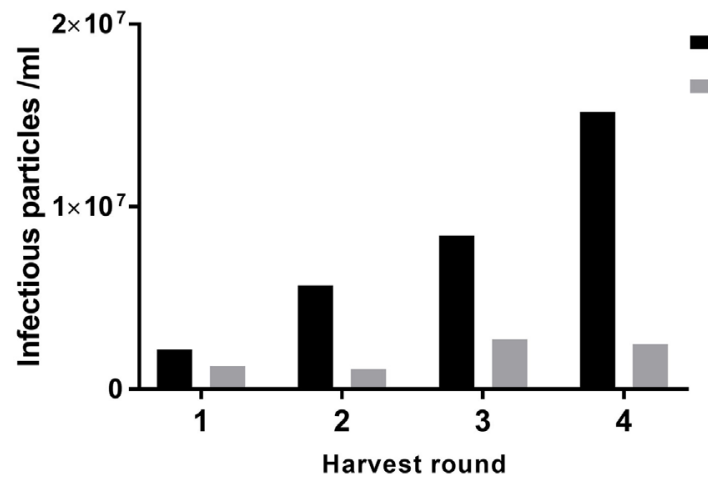

FIGURE 2 | Selection of a viral vector producer cell clone. Retroviral supernatant was produced in 293 vec-RD114 packaging cells. (A) The titer produced by the different clones was assessed in Jurkat cells. The clones depicted by the black bars were selected for a second round of testing (B). (C) Clone \#73 was picked for production of the TEG001 Good Manufacturing Practice retroviral supernatant. The titer was assessed after four rounds of harvest, before, and after filtration.

and 6 (both $0.25 \times 10^{6} / \mathrm{ml}$ ), and day 8 and 10 (both $1.0 \times 10^{6} / \mathrm{ml}$ ). The percentage of $\gamma \delta$ TCR-positive T cells was determined after 7 and 10 days by flow cytometry using a pan- $\gamma \delta$ TCR antibody (Figure 3B). Differences in TEG transduction efficiencies were only observed for very low virus titer conditions $\left(0.03 \times 10^{6}\right.$ $\mathrm{ip} / \mathrm{ml}$ ). A cell concentration of $0.5 \times 10^{6} / \mathrm{ml}$ was selected as the standard cell density during transduction for TEG001 manufacturing process.

\section{Impact of GMP-Grade Virus Titer From Clone \#73 on Transduction Efficiency}

Due to procedural differences between the manufacturing of research-grade and GMP-grade retroviral supernatant, the relationship between virus titer and transduction efficiency for the final GMP viral supernatant batch, which will be used for the production of TEGs for the clinical trial, was further investigated. 

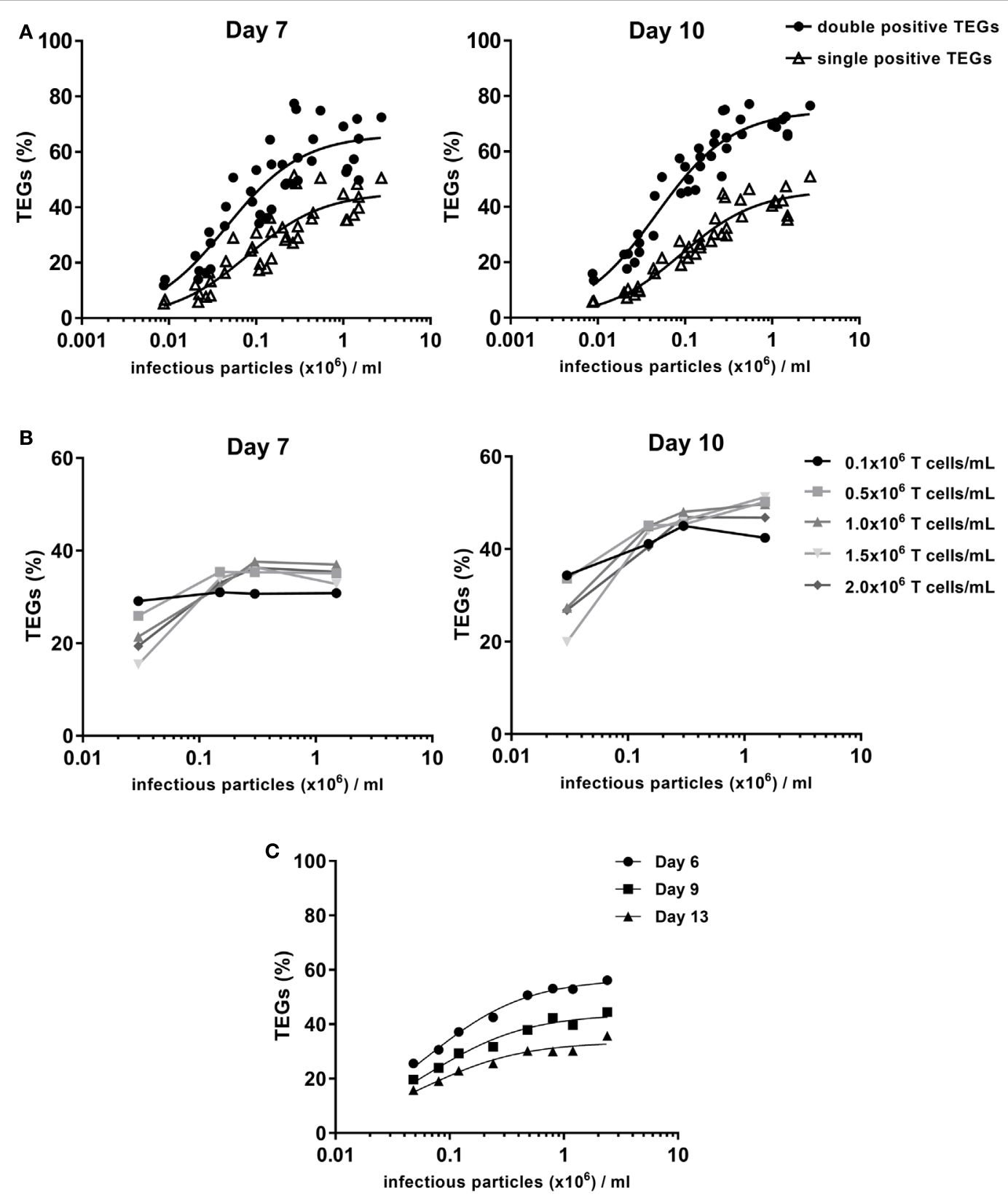

FIGURE 3 | Transduction efficiency depends on the virus titer. T cells were activated with 1:5 CD3/CD28 bead to cell ratio followed by retroviral transduction with the $\gamma \delta$ TCR and expansion. (A) $0.5 \times 10^{6}$ cells per ml were transduced with different concentrations of pre-Good Manufacturing Practice (GMP) viral supernatant. The \% TEGs are shown as total double positive TEGs (black circles) and single positive TEGs (open triangles) at day 7 and day 10 after activation. (B) The relationship between $T$ cell concentration and transduction efficiency was investigated. Transduction efficiency was evaluated after a 7- and 10-day expansion period, for a range of T cell concentrations during transduction and four different virus titers. (C) $0.5 \times 10^{6}$ cells $/ \mathrm{ml}$ were transduced with different concentrations of GMP viral supernatant to determine the relationship between virus titer and transduction efficiency after a 6-, 9-, and 13-day expansion period.

T cells were transduced at a density of $0.5 \times 10^{6}$ cells $/ \mathrm{ml}$ with different dilutions of GMP-grade viral supernatant in a onespin hit transduction procedure. The transduction efficiency and total $\gamma \delta$ TCR positive cell numbers were evaluated after 6,9 , and 13 days by flow cytometry using a pan- $\gamma \delta$ TCR antibody (Figure 3C). The percentage of TEGs with the different pre-GMP titers was highest between day 6 (Figure 3C) and day 10 (data not shown) followed by a small decrease, most likely in line with our previous observation that engineered immune cells have a slight disadvantage in proliferative capacity early after transduction when compared to non engineered immune cells (19). In line with the observation for pre-GMP-grade viral supernatant, the final GMP-grade viral supernatant that will be used for the clinical study provided transduction efficiencies of up to $60 \%$ TEGs when utilizing a titer of $1.2 \times 10^{6} \mathrm{ip} / \mathrm{ml}$ (Figure 3C). 


\section{Higher $\gamma \delta$ TCR Expression Increases Antitumor Activity}

Defining a potency assay for a medicinal product is critical for assessing whether the final product is biologically active. Previous reports suggested that $\gamma \delta$ TCR expression levels correlate with activity of TEGs $(5,8)$. To formally confirm that indeed $\gamma \delta$ TCR expression is key for TEG activity, we used a defined CD4+ T cell clone (20), which underwent the transduction procedure but remained untransduced ( $\mathrm{T}$ cells $\mathrm{A}$ ) or was transduced with the MP71:TCR $\gamma 5$-T2A-TCR 55 retroviral vector, resulting in low and intermediate $\gamma \delta$ TCR single positive cell lines ( $\mathrm{T}$ cells B and C, respectively). Primary T cells from a GMP proof run were used to generate the cell line with a high single positive $\gamma \delta T C R$ fraction that was further purified for CD4+ T cells by CD4 MACS selection after transduction ( $\mathrm{T}$ cells D) (Figure 4A). Next, activity of theses $\gamma \delta$ TCR cell lines with different amounts of single $\gamma \delta$ TCR-positive
T cells was compared side by side in the presence of pamidronate against Daudi as a positive, or ML1 as a negative tumor target (Figure 4B). CD4+ TEGs with higher $\gamma \delta T C R$ expression had a higher activity in terms of IFN $\gamma$ cytokine secretion when compared to CD4+ T cell clones with lower or literally absent $\gamma \delta \mathrm{TCR}$ expression. As control, T cells A-C, which express an endogenous allogeneic HLA-DPB ${ }^{\star} 04$ :01-reactive $\alpha \beta \mathrm{TCR}$, were coincubated with an HLA-DPB1*04:01 expressing B cell line. This resulted in cytokine levels equivalent or higher than from $\mathrm{T}$ cells $\mathrm{D}$, indicating that T cells A-C were highly functional when triggered by the endogenous TCR (data not shown). These data are in line with previous reports from our group (8) and support the rationale to enrich in the GMP process only for TEGs with highest $\gamma \delta \mathrm{TCR}$ expression. Therefore, we defined $\gamma \delta$ TCR-positive expression as a potency assay for TEGs and $\gamma \delta$ TCR single positive TEGs defines the functionally most active population.
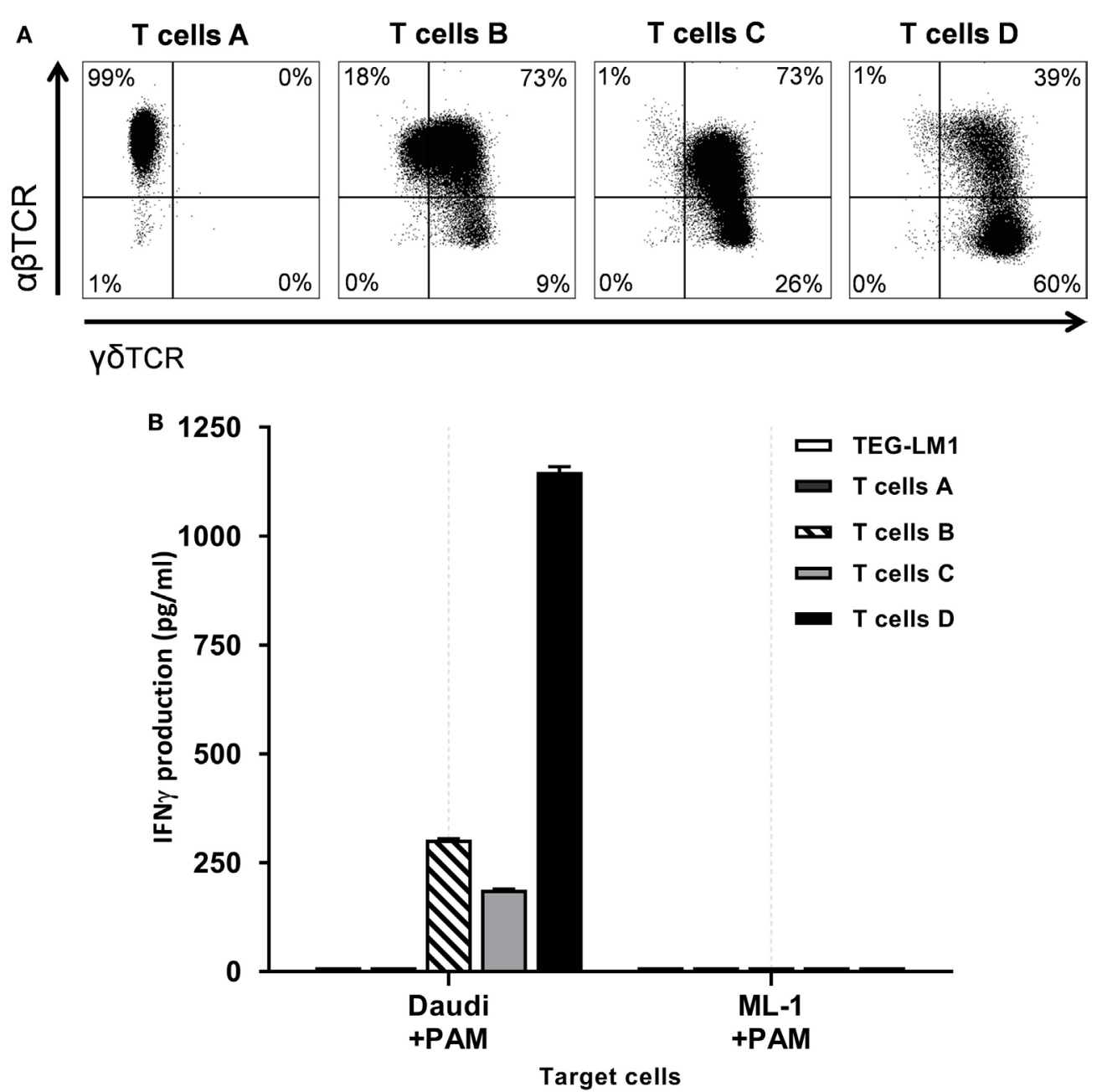

FIGURE $4 \mid \gamma \delta$ TCR expression defines functional activity. (A) A defined CD4+ T cell clone (20) underwent the transduction procedure but remained untransduced ( $T$ cells A) or was transduced with the MP71:TCR $\gamma 5-T 2 A-T C R \delta 5$ retroviral vector, resulting in low and intermediate $\gamma \delta T C R$ single positive cell lines (T cells B and C, respectively). Primary $T$ cells were used to generate the cell line with a high single positive $\gamma \delta T C R$ fraction that was further purified for CD4+ $T$ cells by CD4 MACS selection after transduction (T cells D). In all cases, after one cycle of expansion, $\gamma \delta \mathrm{TCR}$ and $\alpha \beta \mathrm{TCR}$ expression was measured in the viable CD $45+$ gate by flow cytometry after which the cells were used in a function assay. (B) Different T cells were coincubated with the indicated tumor target cell lines in the presence of pamidronate in triplicate. Daudi is the prototypic TEG001 positive target, ML-1 is the negative control target. TEG-LM1 served as the negative control effector. After $20 \mathrm{~h}$ at $37^{\circ} \mathrm{C}$, supernatant was harvested and analyzed by IFN $\gamma$ ELISA. Mean IFN $\gamma$ production + SD is shown. 


\section{Enrichment of TEGs by CliniMACS Through Depletion of Non- and Poorly-Engineered Immune Cells}

Non- and poorly-engineered cell fractions are usually present in genetically engineered $\mathrm{T}$ cell products and associate with little or no activity as shown also for TEG001 (Figures 4A,B). In addition, such cell fractions could even be harmful as they might harbor unwanted specificities. To avoid this potential drawback, a procedure for the depletion of non- and poorly-engineered $\mathrm{T}$ cells was developed by taking advantage of the observation that upon introduction of a $\gamma \delta \mathrm{TCR}$, the endogenous $\alpha \beta \mathrm{TCR}$ expression is substantially decreased or even absent $(2,5)$. First, we defined "in process controls." During six large-scale proof runs, the percentage of $\gamma \delta$ TCR-positive cells was, therefore, assessed at day 6 (in process control), before and after the CliniMACS depletion procedure. Between 31 and $63 \%$ of all cells were positive for $\gamma \delta$ TCR at day 6 , and $73-92 \%$ at day 13 after CliniMACS depletion (Figure 5A). In addition, we assessed the robustness of the
A

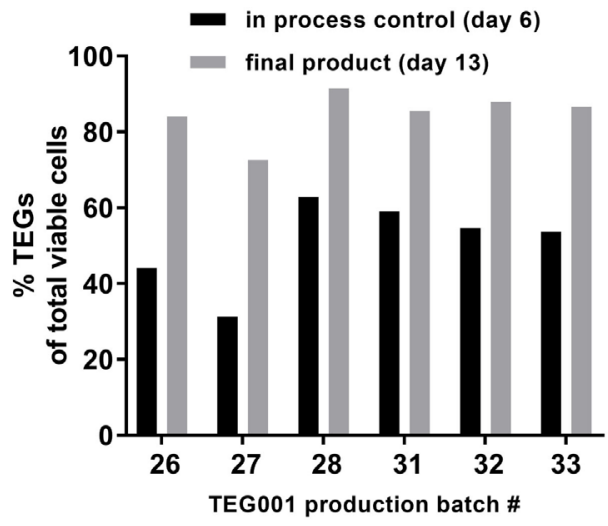

C

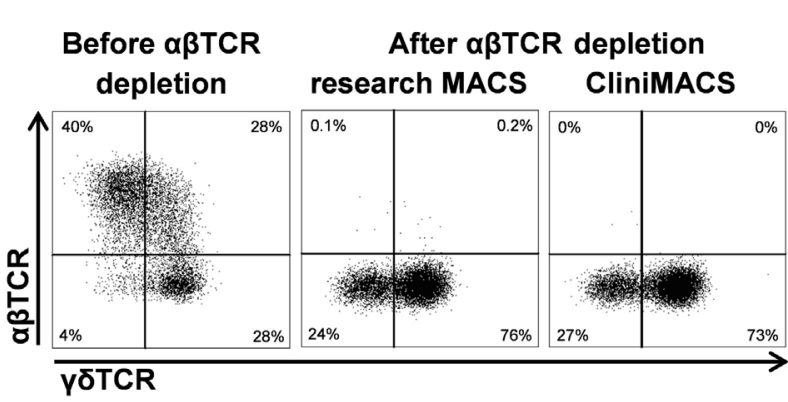

After $\alpha \beta T C R$ depletion

E

$T$ cell activation with $\mathrm{CD} 3 / \mathrm{CD} 28$ beads and IL-7/IL-15
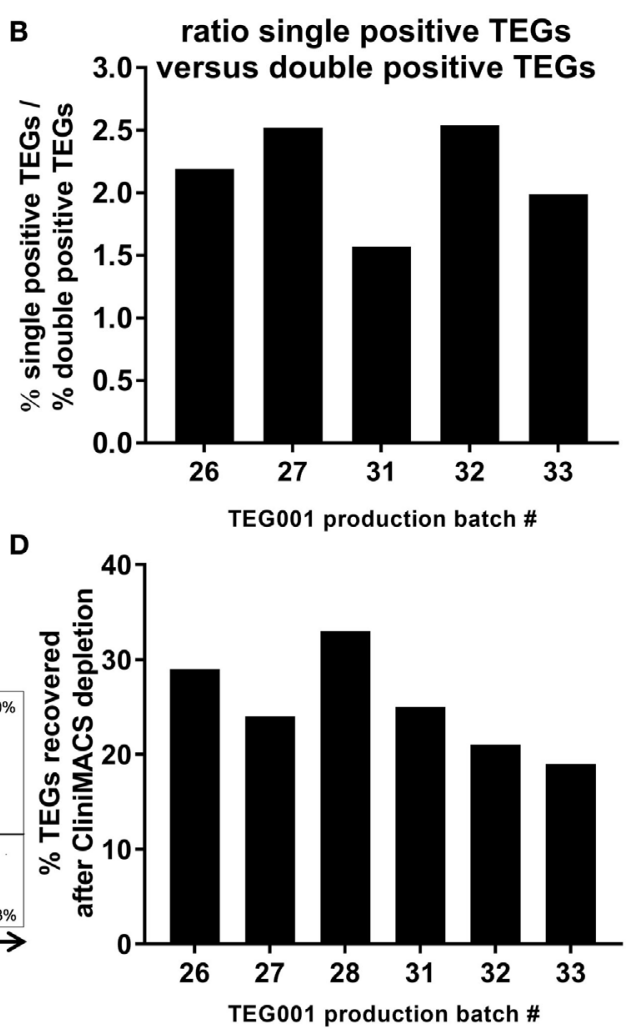

D

- Concentration and bead removal

- $\alpha \beta T C R+T$ cell depletion with CliniMACS

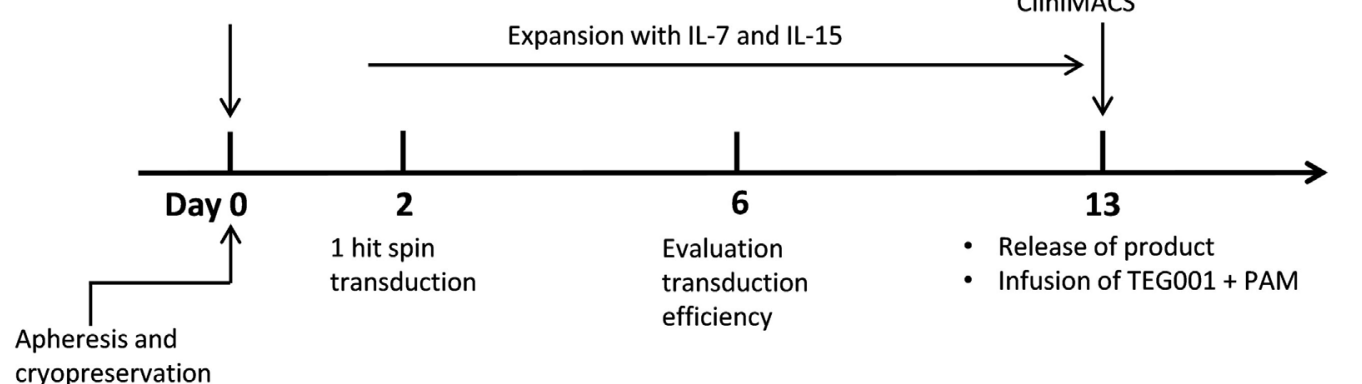

FIGURE 5 | Successful enrichment of TEGs by CliniMACS depletion. (A) Comparison of TEGs transduction efficiency during production (in-process control, day 6) and at the end of production (final product) of six different production batches. (B) After introduction of pMP71: $\gamma$ TCR-T2A- $\delta$ TCR and expansion of the T cells both $\gamma \delta T C R+\alpha \beta T C R-T$ cells as $\gamma \delta$ TCR $+\alpha \beta T C R+T$ cells are present. (C) During one of the research scale production batches, the cells at Day 13 were split and the non-transduced T cells were depleted using the research MACS or CliniMACS cell separation systems. (D) $\gamma \delta T C R+$ cell recovery as percentage of the $\gamma \delta T C R+$ cell input was measured after each $\alpha \beta$ TCR CliniMACS depletion. (E) Overview of the Good Manufacturing Practice TEG001 production process. 
observation that introducing $\gamma \delta \mathrm{TCR}$ substantially outcompetes endogenous $\alpha \beta$ TCRs during different GMP runs. The ratio of single positive to double positive TEGs ranged between 1.6 and 2.5 and was above 1.5 for all runs (Figure 5B). Then, we aimed to assess whether a depletion of non- and poorly-engineered TEGs could not only be performed with research devices (8), but also with GMP-grade $\alpha \beta$ TCR beads on a CliniMACS device. Therefore, we compared side by side the research-scale and largescale depletion of non- and poorly-engineered TEGs through $\alpha \beta$ TCR depletion on a CliniMACS. After the depletion procedure, we observed a comparable purity of single positive TEGs after both procedures (research-grade: $73 \%$ versus clinical-grade: $76 \%$; Figure $5 \mathrm{C}$ ), while the remaining $\alpha \beta \mathrm{TCR}$ positive $\mathrm{T}$ cell fraction was very low for both research-grade and GMP-grade ( 0.3 and $0.0 \%$, respectively). The $\alpha \beta T C R$ negative $\gamma \delta T C R$ negative populations present in both research-grade and GMP-grade depleted products (24 and $27 \%$, respectively) mainly consisted of NK cells (data not shown). This double negative population was present at the end of all manufacturing runs $(n=6$, range $8-27 \%)$, and was donor and batch dependent. The recovery after CliniMACS $\alpha \beta$ TCR depletion, indicated as percentage of $\gamma \delta \mathrm{TCR}+\mathrm{T}$ cell output of the respective input, varied between 19 and $33 \%(n=6$, Figure 5D). This procedure allowed us to produce TEGs in numbers up to $2 \times 10^{9}$ cells and is, therefore, sufficient to deliver dosages needed for the planned clinical study. The complete manufacturing schedule is depicted in Figure 5E.

\section{Immunological Phenotype of TEG001 Drug Substance}

Next, we characterized the immunological phenotype of the drug substance TEG001, as the in vivo proliferation capacity and function of genetically modified cell therapy products is not only determined by the introduced receptor but also by the differentiation phenotype of the individual $\mathrm{T}$ cells. The differentiation phenotype of TEGs was determined by measuring the expression of CD27 and CD45RO (21) of five pre-GMP production runs. The major subset of TEGs was, after a 2 -week expansion period, $\mathrm{T}$ cells with an effector $\left(\mathrm{T}_{\text {eff }}\right)$ and effector memory $\left(\mathrm{T}_{\mathrm{em}}\right)$ phenotype (Figure 6A). In addition, all products contained engineered central memory $\mathrm{T}$ cells $\left(\mathrm{T}_{\mathrm{cm}}\right)$, an immune subset enabling potential long-term persistence of TEG in vivo (22).

\section{Release Specifications of TEG001 Drug Substance and TEG001 Drug Product, Batch Analyses, and Stability}

Release specifications are an essential component of quality assurance and protect the patient from receiving a suboptimal cellular product. Based on our small-scale runs, we defined, therefore, product release specifications. To avoid overly stringent product definition criteria, which could result in the discarding of a product for clinical use, we defined release criteria for the TEG001 drug substance as $\geq 50 \% \gamma \delta$ TCR positive T cells, $\geq 70 \%$ viability, and $\leq 10 \%$ $\alpha \beta$ TCR positive $\mathrm{T}$ cells in addition to standard microbiological release criteria (Table 1). All six large-scale runs met these release criteria as indicated in Table 2 . In addition, after formulation of the drug product, stability of TEG001 drug product was assessed. This is essential for clinical practice as products are frequently administered for logistical reasons within 1 day after production is complete. Therefore, a fraction of TEG001 drug product was stored for 16 and $20 \mathrm{~h}$ at $4^{\circ} \mathrm{C}$ and tested for viability over time. All three tested batches remained stable over the tested time period
A

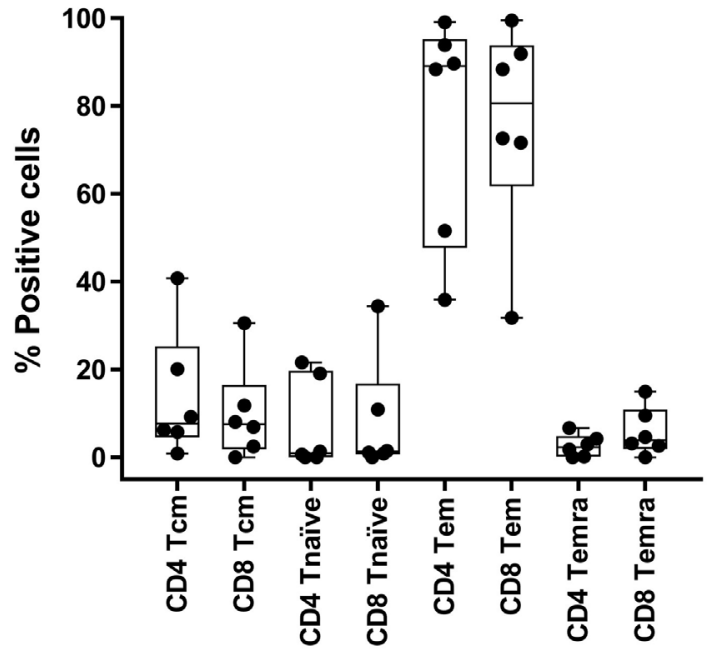

B

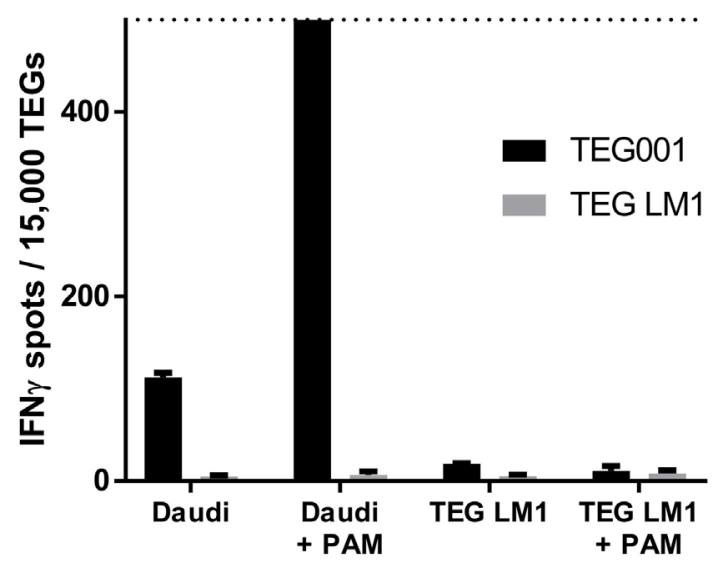

FIGURE 6 | TEGs have a predominant effector-memory/effector phenotype. (A) The phenotype of TEGs from four different donors was determined by measuring CD45RO in combination with CD27 expression on day 13, after the CliniMACS depletion. CD45RO+/CD27+ is considered as $T_{\mathrm{cm}}, \mathrm{CD} 45 \mathrm{RO}-/ \mathrm{CD} 27+$ as $T_{\mathrm{n}}$, CD45RO+/CD27- as $T_{\text {em }}$, and CD45RO-/CD27 - as Temra (21). (B) TEGs were produced according to the described procedure after which they were stored at $2-8^{\circ} \mathrm{C}$. After $20 \mathrm{~h}$, the TEGs were coincubated with Daudi in the absence and presence of pamidronate (PAM) as a positive target, or TEG LM1 in the absence and presence of PAM as a negative target. TEG LM1 as effector served as the negative control. The maximum assay sensitivity was set at 500 spots (dashed line). 
(Table 3). Next, we tested whether GMP-grade TEG001 drug product is functional after storage for $20 \mathrm{~h}$ at $4^{\circ} \mathrm{C}$, by co-incubation of TEG001 and TEG-LM1 (mock control) with the reference target cell line Daudi, in the presence of pamidronate $(2,8)$. TEG001 was effective in recognizing Daudi, while there was no recognition by mock TEGs when assessed by IFN $\gamma$ ELISPOT (Figure 6B).

TABLE 1 | Release specifications TEG001 drug substance.

\begin{tabular}{llc}
\hline Parameter & Method & Acceptance criteria \\
\hline $\begin{array}{ll}\text { Identity } \\
\text { - TEG001 }\end{array}$ & Flow cytometry & Identity confirmed \\
Purity & & $\geq 50 \%$ \\
- $\% \gamma \delta$ TCR-positive T cells & Flow cytometry & $\geq 70 \%$ \\
- Viability & Manual cell count & \\
Impurities & & $\leq 10 \%$ \\
- $\% \alpha \beta$ TCR-positive T cells & \\
Microbiology & Flow cytometry & Negative \\
- Sterility & & Negative \\
- Mycoplasma & Ph.Eur & $<2.0 \mathrm{IU} / \mathrm{ml}$ \\
- Endotoxins & Ph.Eur & Ph.Eur \\
\hline
\end{tabular}

The TEG001 release specifications as defined in the investigational medicinal product dossier.

${ }^{a}$ Only applicable for patients who previously received an allogeneic hematopoietic stem cell transplantation.

\section{DISCUSSION}

We have developed a robust GMP-grade TEG production protocol, which not only includes a conventional transduction and expansion step but also a very stringent CliniMACS enrichment procedure to guarantee high purity of the drug substance. This purification procedure can be used for any engineered immune cell product, which associates with a reduced expression of the $\alpha \beta$ TCR, like CAR-T introduced in the $\alpha$ TCR locus $(23,24)$. By utilizing this protocol, we have been able to produce and enrich TEGs in numbers, which are sufficient to reach the highest dose level of our upcoming phase I trial NTR6541. Furthermore, we have shown that $\gamma \delta$ TCR expression can be used as potency assay for TEG001, and that the TEG001 drug product is stable for at least $20 \mathrm{~h}$ at $4^{\circ}$, which allows for provisional release and transportation to the location of the infusion.

In current manufacturing processes of CAR-T cells, purification steps are often not included. As a consequence, final products currently infused into patients harbor only between 15 and 55\% of engineered immune cells $(18,25,26)$. The lack of purity can become a major clinical obstacle, in particular, when engineering $\mathrm{T}$ cells from patients who relapse after allogeneic stem cell transplantation. Re-infusion of CAR-T cells in patients after allogenic stem cell transplantation has been reported to associate

TABLE 2 | TEG001 drug substance batch analysis data of large scale runs.

\begin{tabular}{|c|c|c|c|c|c|c|c|}
\hline \multirow[t]{2}{*}{ Parameter } & \multirow[t]{2}{*}{ Acceptance criteria } & \multicolumn{6}{|c|}{ Run } \\
\hline & & 26 & 27 & 28 & 31 & 32 & 33 \\
\hline \multicolumn{8}{|l|}{ Identity } \\
\hline - TEG001 & Identity confirmed & Pass & Pass & Pass & Pass & Pass & Pass \\
\hline \multicolumn{8}{|l|}{ Purity } \\
\hline - $\% \gamma \delta$ TCR-positive T cells & $\geq 50 \%$ & $84 \%$ & $73 \%$ & $92 \%$ & $86 \%$ & $88 \%$ & $87 \%$ \\
\hline - Viability & $\geq 70 \%$ & $99 \%$ & $98 \%$ & $99 \%$ & $97 \%$ & $100 \%$ & $100 \%$ \\
\hline \multicolumn{8}{|l|}{ Impurities } \\
\hline - $\quad \% \alpha \beta$ TCR-positive T cells ${ }^{a}$ & $\leq 10 \%$ & $0.0 \%$ & $0.0 \%$ & $0.2 \%$ & $0.5 \%$ & $0.4 \%$ & $0.1 \%$ \\
\hline \multicolumn{8}{|l|}{ Microbiology } \\
\hline - Sterility & Negative & ND & ND & Negative & Negative & ND & ND \\
\hline - Mycoplasma & Negative & ND & ND & Negative & Negative & ND & ND \\
\hline - Endotoxins & $<2.0 \mathrm{IU} / \mathrm{ml}$ & ND & ND & Pass & Pass & ND & ND \\
\hline
\end{tabular}

TEG001 was produced using our Good Manufacturing Practice large scale production protocol in multiple large scale manufacturing runs. TEG001 was formulated after which the identity, purity, and viability was assessed using trypan blue exclusion and flow cytometry.

anly applicable for patients who previously received an allogeneic hematopoietic stem cell transplantation.

TABLE 3 | Stability data of TEG001 cell suspension for infusion stored at $2-8^{\circ} \mathrm{C}$.

\begin{tabular}{|c|c|c|c|c|c|c|c|c|}
\hline \multirow[t]{3}{*}{ Time point } & \multirow[t]{3}{*}{ Parameter } & \multicolumn{7}{|c|}{ Run (content TEG001 cells per $100 \mathrm{ml}$ drug product) } \\
\hline & & 31 & 31 & 32 & 32 & 32 & 33 & 33 \\
\hline & & $69 \times 10^{6}$ & $12 \times 10^{7}$ & $71 \times 10^{6}$ & $14 \times 10^{7}$ & $26 \times 10^{7}$ & $73 \times 10^{7}$ & $31 \times 10^{7}$ \\
\hline \multirow{2}{*}{$\begin{array}{l}\text { Formulation } \\
\mathrm{T}=0 \mathrm{~h}\end{array}$} & Viability & $97 \%$ & $97 \%$ & $100 \%$ & $100 \%$ & $100 \%$ & $100 \%$ & $99 \%$ \\
\hline & Viable cell number recovery & $100 \%$ & $100 \%$ & $100 \%$ & $100 \%$ & $100 \%$ & $100 \%$ & $100 \%$ \\
\hline \multirow{2}{*}{$\begin{array}{l}\text { Storage } \\
\mathrm{T}=16 \mathrm{~h}\end{array}$} & Viability & $96 \%$ & $97 \%$ & $99 \%$ & $100 \%$ & $99 \%$ & $100 \%$ & $100 \%$ \\
\hline & Viable cell number recovery & $93 \%$ & $94 \%$ & $99 \%$ & $94 \%$ & $90 \%$ & $100 \%$ & $97 \%$ \\
\hline \multirow{2}{*}{$\begin{array}{l}\text { Storage } \\
T=20 \mathrm{~h}\end{array}$} & Viability & $94 \%$ & $94 \%$ & $100 \%$ & $100 \%$ & $99 \%$ & $100 \%$ & $100 \%$ \\
\hline & Viable cell number recovery & $84 \%$ & $94 \%$ & $99 \%$ & $94 \%$ & $90 \%$ & $97 \%$ & $97 \%$ \\
\hline
\end{tabular}

TEG001 was produced using our Good Manufacturing Practice large scale production protocol in multiple large scale manufacturing runs. TEG001 was formulated in NaCl $0.9 \%$ for infusion with 4\% HA at different cellular concentrations, to study the effect of TEGs density on cell viability and viable cell recovery at $T=0$ and after storage at 2-8 ${ }^{\circ} \mathrm{C}$ for 16 and $20 \mathrm{~h}$. 
with incidences of acute and chronic graft versus host disease (GvHD), up to $10 \%$ (27). GvHD after infusion of CAR-T cells is most likely a consequence of endogenous $\alpha \beta$ TCRs still expressed at physiological levels in CAR-T cells, as well as the presence of non-engineered immune cells within the product. With our TEG concept, we provide comprehensive solutions to these problems. First, as suggested from our previous data, not only in the research environment (8) but also with our presented GMP manufacturing process, endogenous $\alpha \beta$ TCRs are substantially downregulated in TEGs. Reduced expression of endogenous $\alpha \beta$ TCRs is most likely due to the efficient competition of the introduced $\gamma \delta$ TCR against endogenous $\alpha \beta$ TCR for CD3 components of a T cell. Second, the additional GMP enrichment procedure utilizing the CliniMACS system achieves purity of TEGs, which can exceed $90 \%$. The removal of non- and poorly-engineered cells from the final drug substance has another advantage, in addition to the reduced risk of GvHD and a more potent product due to enrichment of $\gamma \delta$ TCR-positive cells; the improved competition for homeostatic cytokines $(28,29)$. Other strategies for the refinement of engineered immune cells have been developed recently. However, alternative purification strategies frequently depend on the introduction of an additional truncated protein such as CD19 or epidermal growth factor receptor, which are normally absent in the $\mathrm{T}$ cell lineage (30). Using a transgene cassette with an additional sequence for selection purposes can lead to lower transduction efficiencies and reduced expression of the introduced immune receptor or alternative homing (J. Kuball, unpublished observation) and associates frequently with unwanted $\mathrm{T}$ cell activation and immunogenicity (31). To the best of our knowledge, we have developed the very first GMP manufacturing procedure in which $\alpha \beta T C R$ depletion is used as a purification method, thereby delivering untouched clinical-grade engineered immune cells. Despite an efficient elimination of non- and poorly-engineered $\alpha \beta T$ cells, our procedure also enriches for NK cells. An additional purification step before $\mathrm{T}$ cell engineering might, therefore, be intriguing for the next generation of TEG-manufacturing, such as $\alpha \beta \mathrm{TCR}+$ or CD3+ cell selection before T cell activation (32), as proposed by others.

Advanced therapy medicinal products (ATMPs), such as TEGs, are individualized and complex biological products that require careful consideration of their nature in order to define adequate "in process" and "release" tests. ATMPs are also frequently freshly prepared and directly infused into patients after production, limiting the possibilities for extensive safety and release testing for an

\section{REFERENCES}

1. Chabannon C, Kuball J, McGrath E, Bader P, Dufour C, Lankester A, et al. CAR-T cells: the narrow path between hope and bankruptcy? Bone Marrow Transplant (2017) 52(12):1588-9. doi:10.1038/bmt.2017.241

2. Grunder C, van Dorp S, Hol S, Drent E, Straetemans T, Heijhuurs S, et al. gamma9 and delta2CDR3 domains regulate functional avidity of $\mathrm{T}$ cells harboring gamma9delta2TCRs. Blood (2012) 120(26):5153-62. doi:10.1182/ blood-2012-05-432427

3. Sebestyen Z, Scheper W, Vyborova A, Gu S, Rychnavska Z, Schiffler M, et al. RhoB mediates phosphoantigen recognition by Vgamma9Vdelta2 T cell receptor. Cell Rep (2016) 15(9):1973-85. doi:10.1016/j.celrep.2016. 04.081

4. Gu S, Sachleben JR, Boughter CT, Nawrocka WI, Borowska MT, Tarrasch JT, et al. Phosphoantigen-induced conformational change of butyrophilin 3A1 individual product. Despite the limited possibilities, regulatory authorities oblige a potency assay before batch release. Potency is defined as "the specific ability or capacity of the product, as indicated by appropriate laboratory tests or by adequately controlled clinical data obtained through the administration of the product in the manner intended, to effect a given result" (33). Potency must be measured in a robust and biologically relevant way, which reflects the mechanism of action. Thus, defining valid potency assays can be a major challenge for ATMPs. For CAR019, expression of the introduced receptor as a potency assay has been proposed by vendors and accepted by the FDA $(17,34)$. We provide now evidence that for TEGs, $\gamma \delta$ TCR expression levels are an adequate potency assay. However, expression levels of receptors are rather simplified and surrogate methods to assess for activity will not predict efficacy in vivo. Therefore, alternative methods are needed. Highthroughput characterization of TEGs on single cell levels could be interesting alternatives, as previously also reported for CAR-T (35).

In conclusion, we have developed a GMP-grade manufacturing strategy for TEGs incorporating an $\alpha \beta T C R$ depletion to obtain a final product substantially enriched for TEGs. The described process can also be valuable for any CAR-T product interfering with endogenous $\alpha \beta$ TCR expression. We also defined release and potency criteria acceptable for competent authorities. TEG001 will be used for an upcoming phase I dose escalation clinical trial registered as NTR6541. This trial aims to investigate the safety and tolerability of TEG001 in patients with relapsed/refractory acute myeloid leukemia, high-risk myelodysplastic syndrome, and relapsed/refractory multiple myeloma.

\section{AUTHOR CONTRIBUTIONS}

JK and TS designed experiments. GK, TS, SH, RD, KJ, and JS performed the experiments, AM reviewed data and submitted documents to authorities; GK, TS, ZS, and JK wrote the manuscript; all authors agreed on the final manuscript.

\section{FUNDING}

Funding for this study was provided by ZonMW 43400003 and VIDI-ZonMW 917.11.337, KWF UU 2010-4669, UU 2013-6426, UU 2014-6790, UU 2015-7601, and UU-2017-11393, Vrienden van het UMCU, AICR 10-0736 and 15-0049 and Gadeta to JK and Lady Tata Memorial Trust to ZS.

(BTN3A1) and its implication on Vgamma9Vdelta2 T cell activation. Proc Natl Acad Sci U S A (2017) 114(35):E7311-20. doi:10.1073/pnas.1707547114

5. Marcu-Malina V, Heijhuurs S, van Buuren M, Hartkamp L, Strand S, Sebestyen Z, et al. Redirecting alphabeta $\mathrm{T}$ cells against cancer cells by transfer of a broadly tumor-reactive gammadeltaT-cell receptor. Blood (2011) 118(1):50-9. doi:10.1182/blood-2010-12-325993

6. Scheper W, Grunder C, Kuball J. Multifunctional gammadelta T cells and their receptors for targeted anticancer immunotherapy. Oncoimmunology (2013) 2(5):e23974. doi:10.4161/onci.23974

7. Scheper W, Grunder C, Straetemans T, Sebestyen Z, Kuball J. Hunting for clinical translation with innate-like immune cells and their receptors. Leukemia (2014) 28(6):1181-90. doi:10.1038/leu.2013.378

8. Straetemans T, Grunder C, Heijhuurs S, Hol S, Slaper-Cortenbach I, Bonig H, et al. Untouched GMP-ready purified engineered immune cells to treat cancer. Clin Cancer Res (2015) 21(17):3957-68. doi:10.1158/1078-0432.CCR-14-2860 
9. Braham MVJ, Minnema MC, Aarts T, Sebestyen Z, Straetemans T, Vyborova A, et al. Cellular immunotherapy on primary multiple myeloma expanded in a 3D bone marrow niche model. Oncoimmunology (2018). doi:10.1080/21624 02X.2018.1434465

10. Ghani K, Cottin S, Kamen A, Caruso M. Generation of a high-titer packaging cell line for the production of retroviral vectors in suspension and serum-free media. Gene Ther (2007) 14(24):1705-11. doi:10.1038/sj.gt.3303039

11. Ghani K, Wang X, de Campos-Lima PO, Olszewska M, Kamen A, Riviere I, et al. Efficient human hematopoietic cell transduction using RD114- and GALV-pseudotyped retroviral vectors produced in suspension and serumfree media. Hum Gene Ther (2009) 20(9):966-74. doi:10.1089/hum.2009.001

12. Levine BL, Bernstein WB, Connors M, Craighead N, Lindsten T, Thompson CB, et al. Effects of CD28 costimulation on long-term proliferation of CD4+ T cells in the absence of exogenous feeder cells. J Immunol (1997) 159(12):5921-30.

13. Brentjens RJ, Riviere I, Park JH, Davila ML, Wang X, Stefanski J, et al. Safety and persistence of adoptively transferred autologous CD19-targeted T cells in patients with relapsed or chemotherapy refractory B-cell leukemias. Blood (2011) 118(18):4817-28. doi:10.1182/blood-2011-04-348540

14. Gomez-Eerland R, Nuijen B, Heemskerk B, van Rooij N, van den Berg JH, Beijnen JH, et al. Manufacture of gene-modified human T-cells with a memory stem/central memory phenotype. Hum Gene Ther Methods (2014) 25(5):277-87. doi:10.1089/hgtb.2014.004

15. Kalos M, Levine BL, Porter DL, Katz S, Grupp SA, Bagg A, et al. T cells with chimeric antigen receptors have potent antitumor effects and can establish memory in patients with advanced leukemia. Sci Transl Med (2011) 3(95):95ra73. doi:10.1126/scitranslmed.3002842

16. Porter DL, Levine BL, Kalos M, Bagg A, June CH. Chimeric antigen receptor-modified T cells in chronic lymphoid leukemia. N Engl J Med (2011) 365(8):725-33. doi:10.1056/NEJMoa1103849

17. Levine BL, Miskin J, Wonnacott K, Keir C. Global manufacturing of CAR T cell therapy. Mol Ther Methods Clin Dev (2017) 4:92-101. doi:10.1016/j. omtm.2016.12.006

18. Lamers CH, Willemsen RA, Luider BA, Debets R, Bolhuis RL. Protocol for gene transduction and expansion of human T lymphocytes for clinical immunogene therapy of cancer. Cancer Gene Ther (2002) 9(7):613-23. doi:10.1038/ sj.cgt. 7700477

19. Voss RH, Kuball J, Theobald M. Designing TCR for cancer immunotherapy. Methods Mol Med (2005) 109:229-56. doi:10.1385/1-59259-862-5:229

20. Gaschet J, Lim A, Liem L, Vivien R, Hallet MM, Harousseau JL, et al. Acute graft versus host disease due to $\mathrm{T}$ lymphocytes recognizing a single HLA-DPB1*0501 mismatch. J Clin Invest (1996) 98(1):100-7. doi:10.1172/ JCI118753

21. Klebanoff CA, Gattinoni L, Restifo NP. CD8+ T-cell memory in tumor immunology and immunotherapy. Immunol Rev (2006) 211:214-24. doi:10.1111/ j.0105-2896.2006.00391.x

22. Sommermeyer D, Hudecek M, Kosasih PL, Gogishvili T, Maloney DG, Turtle CJ, et al. Chimeric antigen receptor-modified $\mathrm{T}$ cells derived from defined CD8+ and CD4+ subsets confer superior antitumor reactivity in vivo. Leukemia (2016) 30(2):492-500. doi:10.1038/leu.2015.247

23. MacLeod DT, Antony J, Martin AJ, Moser RJ, Hekele A, Wetzel KJ, et al. Integration of a CD19 CAR into the TCR alpha chain locus streamlines production of allogeneic gene-edited CAR T cells. Mol Ther (2017) 25(4):949-61. doi:10.1016/j.ymthe.2017.02.005

24. Legut M, Dolton G, Mian AA, Ottmann O, Sewell A. CRISPR-mediated TCR replacement generates superior anticancer transgenic T-cells. Blood (2018) 131(3):311-22. doi:10.1182/blood-2017-05-787598
25. Lock D, Mockel-Tenbrinck N, Drechsel K, Barth C, Mauer D, Schaser T, et al Automated manufacturing of potent CD20-directed chimeric antigen receptor T cells for clinical use. Hum Gene Ther (2017) 28(10):914-25. doi:10.1089/ hum.2017.111

26. Hodi FS, O’Day SJ, McDermott DF, Weber RW, Sosman JA, Haanen JB, et al. Improved survival with ipilimumab in patients with metastatic melanoma. N Engl J Med (2010) 363(8):711-23. doi:10.1056/NEJMoa1003466

27. Smith M, Zakrzewski J, James S, Sadelain M. Posttransplant chimeric antigen receptor therapy. Blood (2018) 131(10):1045-52. doi:10.1182/blood2017-08-752121

28. Abad JD, Wrzensinski C, Overwijk W, De Witte MA, Jorritsma A, Hsu C, et al. T-cell receptor gene therapy of established tumors in a murine melanoma model. J Immunother (2008) 31(1):1-6. doi:10.1097/CJI.0b013e31815c193f

29. de Witte MA, Jorritsma A, Kaiser A, van den Boom MD, Dokter M, Bendle GM, et al. Requirements for effective antitumor responses of TCR transduced T cells. J Immunol (2008) 181(7):5128-36. doi:10.4049/jimmunol.181.7.5128

30. Gardner RA, Finney O, Annesley C, Brakke H, Summers C, Leger K, et al. Intent-to-treat leukemia remission by CD19 CAR T cells of defined formulation and dose in children and young adults. Blood (2017) 129(25):3322-31. doi:10.1182/blood-2017-02-769208

31. Traversari C, Marktel S, Magnani Z, Mangia P, Russo V, Ciceri F, et al. The potential immunogenicity of the TK suicide gene does not prevent full clinical benefit associated with the use of TK-transduced donor lymphocytes in HSCT for hematologic malignancies. Blood (2007) 109(11):4708-15. doi:10.1182/blood-2006-04-015230

32. Neurauter AA, Bonyhadi M, Lien E, Nokleby L, Ruud E, Camacho S, et al. Cell isolation and expansion using Dynabeads. Adv Biochem Eng Biotechnol (2007) 106:41-73. doi:10.1007/10_2007_072

33. FDA. 21 CFR 600.3(s). (2017). Available from: https://www.gpo.gov/fdsys/pkg/ CFR-2011-title21-vol7/pdf/CFR-2011-title21-vol7-sec600-3.pdf (Accessed: January 25, 2018).

34. FDA. BLA 125646 - Tisagenlecleucel. (2017). Available from: https://www.fda. gov/downloads/AdvisoryCommittees/CommitteesMeetingMaterials/Drugs/ OncologicDrugsAdvisoryCommittee/UCM566166.pdf (Accessed: January $25,2018)$.

35. Xue Q, Bettini E, Paczkowski P, Ng C, Kaiser A, McConnell T, et al. Singlecell multiplexed cytokine profiling of CD19 CAR-T cells reveals a diverse landscape of polyfunctional antigen-specific response. J Immunother Cancer (2017) 5(1):85. doi:10.1186/s40425-017-0293-7

Conflict of Interest Statement: GK, ZS, and JK are inventors on different patents with $\gamma \delta$ TCR sequences, recognition mechanisms, and isolation strategies. JK is $\mathrm{CSO}$ and shareholder of Gadeta (www.gadeta.nl). The remaining authors declare that the research was conducted in the absence of any commercial or financial relationships that could be construed as a potential conflict of interest.

The reviewer JA and handling Editor declared their shared affiliation.

Copyright (C) 2018 Straetemans, Kierkels, Doorn, Jansen, Heijhuurs, dos Santos, van Muyden, Vie, Clemenceau, Raymakers, de Witte, Sebestyén and Kuball. This is an open-access article distributed under the terms of the Creative Commons Attribution License (CC BY). The use, distribution or reproduction in other forums is permitted, provided the original author(s) and the copyright owner are credited and that the original publication in this journal is cited, in accordance with accepted academic practice. No use, distribution or reproduction is permitted which does not comply with these terms. 